\title{
The use of sodium nitroprusside as a hypotensive agent in plastic surgery
}

\author{
J. B. Hester \\ F.F.A.R.C.S. \\ Queen Victoria Hospital, East Grinstead, Sussex
}

\begin{abstract}
Summary
Sodium nitroprusside was used to induce hypotensive anaesthesia in twelve fit patients undergoing plastic surgery. Marked individual variation in response occurred, steady low levels of blood pressure being difficult to maintain. Response to halothane, posture and increased airways pressure was also studied.
\end{abstract}

THE use of sodium nitroprusside for hypotension during plastic surgical operations has been investigated at the Queen Victoria Hospital, East Grinstead, in a series of twelve cases. An attempt has been made to compare its effectiveness with that of the pharmacological blockers, and to determine whether controls such as posture and respiration are similarly responsible for its hypotensive action.

The series consisted of six male and six female patients whose ages ranged from 23 to 65 years. They were all normotensive pre-operatively and no patient had a history of cardiac, cerebral or chest disease.

The operations performed were four nasal reductions, one abdominal reduction, two operations on the buttock and back for an extensive naevus, one facial hair transplant and four operations on the extremities. All operations on the head and neck and abdomen were performed in the foot down position, with an angle of tilt of approximately $20-30^{\circ}$. The naevus operation was in the prone position, whilst those on the extremities were performed under tourniquet, and hypotension induced immediately before its release.

All patients were premedicated with levorphan $1-1.5 \mathrm{mg}$, phenergan $25 \mathrm{mg}$ and hyoscine $0.4 \mathrm{mg}$ $1 \mathrm{hr}$ pre-operatively. Anaesthesia was induced with thiopentone $2.5 \%$, and intubation performed under suxamethonium together with decamethonium $5 \mathrm{mg}$ to facilitate controlled ventilation. Maintenance was with oxygen, $30-50 \%$ nitrous oxide, and halothane $1-2 \%$. Two cases also received methoxyflurane. Those patients below 40 years of age were given a small dose of a $\beta$-adrenergic blocker, either propranolol (1.0-1.5 mg), or practolol (5-8 mg). Intermittent positive pressure ventilation was maintained in all cases using a semi-closed circle absorber system.

An intravenous infusion of $5 \%$ dextrose was then commenced in all patients. In eight of these $5-10 \mathrm{ml}$ of $1 \%$ sodium nitroprusside was added to $500 \mathrm{ml}$ dextrose. In the remaining four patients intermittent injections of a dilute solution of sodium nitroprusside $(0.5 \mathrm{mg} / \mathrm{ml})$ were made from a $20 \mathrm{ml}$ syringe. The sodium nitroprusside infusion was started just before surgery, and maintained until the desired level of blood pressure was obtained, this being estimated on a Boulitte Oscillometer. An attempt was then made to maintain a constant hypotension by adjustment of drip rate. When this hado been achieved the effects of varying halothane con centrations, alterations of the angle of table tilt, and variations in airway pressure were performed in order to determine their effects on blood pressure.

After surgery the patients were extubated and returned to the recovery ward, where the dextrose drip was maintained until the circulation was stable. In practice this was for a brief period of 15-30 min only, but blood pressure and pulse rate were observed for $3 \mathrm{hr}$ thereafter.

\section{Results}

Cutaneous vasodilation, as shown by flushing of the face and trunk, appeared in most patients shortly after the initial dose of sodium nitroprusside.

Tachycardia occurred initially in all patients as the blood pressure fell, but the pulse tended to slow when a hypotension of $60-80 \mathrm{mmHg}$ was achieved.

There was marked individual variation in the hypotensive response. Although all patients responded with an initial fall in blood pressure, the amount of sodium nitroprusside necessary to maintain a hypotension of $50-70 \mathrm{mmHg}$ was very variable, the dosage varying from a minimum of $4 \mathrm{mg}$ to a maximum of $250 \mathrm{mg}$ during a $30 \mathrm{~min}$ period.

In half of the patients there were such marked fluctuations of blood pressure that maintenance at a constant level proved impossible. The surgical fields in these patients were poor, and in our experience 
markedly inferior to those obtained by our usual technique of pharmacological blockade.

Other factors which influenced the hypotension of sodium nitroprusside were as follows.

(1) Age: the older patient was often more sensitive, and required a smaller total dose of sodium nitroprusside.

(2) Sex: there was no apparent difference between the sexes in their response to this drug.

(3) Increasing halothane concentrations assisted and maintained a more stable hypotension.

(4) Tilting the table from horizontal to head-up $10-20^{\circ}$ further decreased blood pressure by an average $10-30 \mathrm{mmHg}$.

(5) Positive airway pressure temporarily decreased blood pressure by $10-20 \mathrm{mmHg}$, but usually this was not maintained, and it was therefore in contrast to the technique of hypotensive control with pharmacological blockers.

In all cases recovery was uneventful, the blood pressure returning to its pre-operative level within 5 min of the end of surgery.

\section{Discussion}

Sodium nitroprusside produces its hypotensive effect by a direct action on the blood vessel wall (Page et al., 1955); it has no direct effect on the myocardium or sympathetic ganglia (Jones et al., 1968). It is metabolized, firstly in the liver to thiocyanate, and then by erythrocyte oxidase to cyanide. The minimal toxic level of cyanide is $0.34 \mathrm{mg} / 100 \mathrm{ml}$ (Siegel et al., 1971). High doses or prolonged per- fusion of sodium nitroprusside may, therefore, carry a risk of cyanide poisoning.

Our results indicate that six out of twelve cases proved unsatisfactory inasmuch as the surgical field and the ease of control of hypotension were much inferior to that obtained with pharmacological blockers. The sodium nitroprusside technique, however, was more easily applicable than the latter, where it was not desirable or possible to employ an effective tilt on the operation table, and also in those cases where only a brief fall in blood pressure was required such as after the release of an exsanguinating tourniquet. This relative lack of success in our hands may have been due partly to our own inexperience, as well as the youth and fitness of the patients, and the nature of the surgery involved.

In summary, therefore, sodium nitroprusside cannot be whole-heartedly recommended as a hypotensive agent in plastic surgery, except for those cases where only brief periods of hypotension are required, and for certain selected operations where posture cannot be used to elevate the site of operation.

\section{References}

Page, I.H., Corcoran, A.C., Dustan, H.P. \& Koppany, T. (1955) Cardiovascular actions of sodium nitroprusside in animals and hypertensive patients. Circulation, 2, 188.

JoNES, G.O.M. \& ColE, P. (1968) Sodium nitroprusside as a hypotensive agent. British Journal of Anaesthesia, 40, 804.

Siegel, P., Moraca, P.P. \& Green, J.R. (1971) Sodium nitroprusside in the surgical treatment of cerebral aneurysms and arteriovenous malformations. British Journal of Anaesthesia, 43, 790. 